\title{
Cyclic Voltammetry and Impedance Spectroscopy Behavior Studies of Polyterthiophene Modified Electrode
}

\author{
Naima Maouche and Belkacem Nessark \\ Laboratoire d'Electrochimie et Matériaux, Département de Génie des Procédés, Faculté de Technologie, Université Ferhat Abbas, \\ 19000 Sétif, Algeria \\ Correspondence should be addressed to Naima Maouche, m_naima2001@yahoo.fr
}

Received 10 May 2011; Accepted 20 June 2011

Academic Editor: José H. Zagal

Copyright (๑) 2011 N. Maouche and B. Nessark. This is an open access article distributed under the Creative Commons Attribution License, which permits unrestricted use, distribution, and reproduction in any medium, provided the original work is properly cited.

\begin{abstract}
We present in this work a study of the electrochemical behaviour of terthiophene and its corresponding polymer, which is obtained electrochemically as a film by cyclic voltammetry (CV) on platinum electrode. The analysis focuses essentially on the effect of two solvents acetonitrile and dichloromethane on the electrochemical behaviour of the obtained polymer. The electrochemical behavior of this material was investigated by cyclic voltammetry and electrochemical impedance spectroscopy (EIS). The voltammograms show that the film of polyterthiophene can oxide and reduce in two solutions; in acetonitrile, the oxidation current intensity is more important than in dichloromethane. The impedance plots show the semicircle which is characteristic of charge-transfer resistance at the electrode/polymer interface at high frequency and the diffusion process at low frequency.
\end{abstract}

\section{Introduction}

As other conjugated conducting polymers, polythiophene and its oligomers can be polymerized from their monomers in solutions by electrochemical methods. The electrochemical synthesis is advantageous method: polymers are formed in the doped state; films generally possess interesting electrochemical and good semiconductor properties [1] and relatively good stability in air for both the neutral and oxidised states [2-7].

The mechanism of the electropolymerisation of conducting polymers and polyheterocycles occurred by the coupling via $\alpha-\alpha$ bonding of monomer radical cation after its oxidation at the electrode, and the protons are removed from dihydrodication leading to neutral species [8-10]. As the dimer is more easily oxidized than the monomer, it is immediately oxidized. The chain elongation occurs by the addition of new monomer radical cation leading to polymerization and forms the insoluble polymeric species, which subsequently deposits onto the electrode [11].

Conducting polymer-modified electrodes have been widely investigated because of their potential application in areas such as electrocatalysis $[12,13]$, sensors [14, 15], corrosion [16-18], batteries [19, 20], electronic displays, and devices [21-24].

In our previous work [25], we have studied the role of P3T in corrosion of stainless steel; the results were important and show effectively that the film of P3T will decrease the corrosion rate. In this paper, we are interested in performing an electrochemical characterisation of $\mathrm{P} 3 \mathrm{~T}$ films electrochemically synthesized, in two organic solvents: acetonitrile $\left(\mathrm{CH}_{3} \mathrm{CN}\right)$ and dichloromethane $\left(\mathrm{CH}_{2} \mathrm{Cl}_{2}\right)$, at platinum substrates. We want to show how the medium of the analysis is depending upon the electrochemical and electronic behaviour of the formed films.

\section{Experimental}

The solvents acetonitrile and dichloromethane, Aldrich pure products for analysis, were used without further purification. Terthiophene (3T) was purchased from Aldrich (98\%), and it was used as received; the supporting electrolyte salt tetrabutylammonium perchlorate (TBAP) was purchased 
from Fluka; this salt was first dried at a temperature of $80^{\circ} \mathrm{C}$ for $4 \mathrm{~h}$ before its use for the preparation of solution.

Electrochemical measurements were carried out on potentiostat/galvanostat Voltalab 40 interfaced with a PC under Voltamaster 4 software, in a three-electrode cell consisting of: platinum working electrode (diameter $2 \mathrm{~mm}$ ), which was served as a substrate for the deposition of polyterthiophene (P3T), wire platinum as auxiliary electrode, and a saturated calomel electrode (SCE) as reference.

Electrochemical impedance spectroscopy measurements were performed using an impedancemeter Z-computer TACUSSEL controlled by microcomputer HEWLETTPACKARD. The assembly is coupled to a plotter and a printer. The impedance spectra were recorded in the frequency range $10^{5} \mathrm{~Hz}-10^{-3} \mathrm{~Hz}$ with an amplitude of $10 \mathrm{mV}$, in three-electrode electrochemical cell. All experiments were carried out at room temperature.

Before the electrochemical deposition of polyterthiophene for each experiment, the working electrode was polished by $0.03 \mu \mathrm{m}$ alumina slurry and rinsed with distilled water and acetone for the removal of excess $3 \mathrm{~T}$ monomer.

\section{Results and Discussion}

3.1. Electropolymerisation of Terthiophene. Figure 1 shows the cyclic voltammograms (12th cycles) $10^{-2} \mathrm{M}$ of $3 \mathrm{~T}$ dissolved in $\mathrm{CH}_{3} \mathrm{CN}$ solution containing $0.1 \mathrm{M}$ of TBAP supporting electrolyte at $\mathrm{Pt}$ electrode, in potential scans between 0 and $1.2 \mathrm{~V}$ versus SCE with scan rate of $50 \mathrm{mV} / \mathrm{s}$. The first scan shows that the terthiophene is oxidized to its radical cation at potential of $+1.07 \mathrm{~V}$ [26], and immediately the polymer was formed. In the reverse cathodic scan, a polymer reduction peak was observed at a potential of $0.70 \mathrm{~V}$. The current of the oxidative peak progressively increases with the number of cycles indicating the formation and the growth of conducting polymer film and suggests that there is systematic increase in the electrode area as a result of the actual deposition of P3T $[27,28]$. The films formed are stable on the electrode and can easily be transferred to an electrolyte solution in absence of monomer.

3.2. Cyclic Voltammetry Characterisation. After polymerization, the working electrode was extracted from the cell, rinsed with acetone, and dried with a gentle nitrogen flux, then analysed by cyclic voltammetry and impedance spectroscopy in the monomer-free solution of $\mathrm{CH}_{3} \mathrm{CN} / \mathrm{TBAP}$ and $\mathrm{CH}_{2} \mathrm{Cl}_{2}$ /TBAP, respectively.

Figure 2 shows the cyclic voltammograms of P3T film in $\mathrm{CH} 3 \mathrm{CN} / 0.1 \mathrm{M}$ of TBAP solution, recorded at different voltage scan rates 10 (a), 20 (b), 50 (c), and $100 \mathrm{mV} / \mathrm{s}$.

The voltammogram recorded at scan rate of $10 \mathrm{mV} / \mathrm{s}$ (inset of Figure 2) shows a single oxidation peak located at $1.06 \mathrm{~V}$ and two reduction processes, one at around $0.96 \mathrm{~V}$ and the other less intense at $0.74 \mathrm{~V}$. However, we observe that, except for their oxidation potential, which depends on the chain length of the oligomer, the shape of voltammetric curves is similar, and the same behavior was also observed with different thiophene oligomers [29-33].

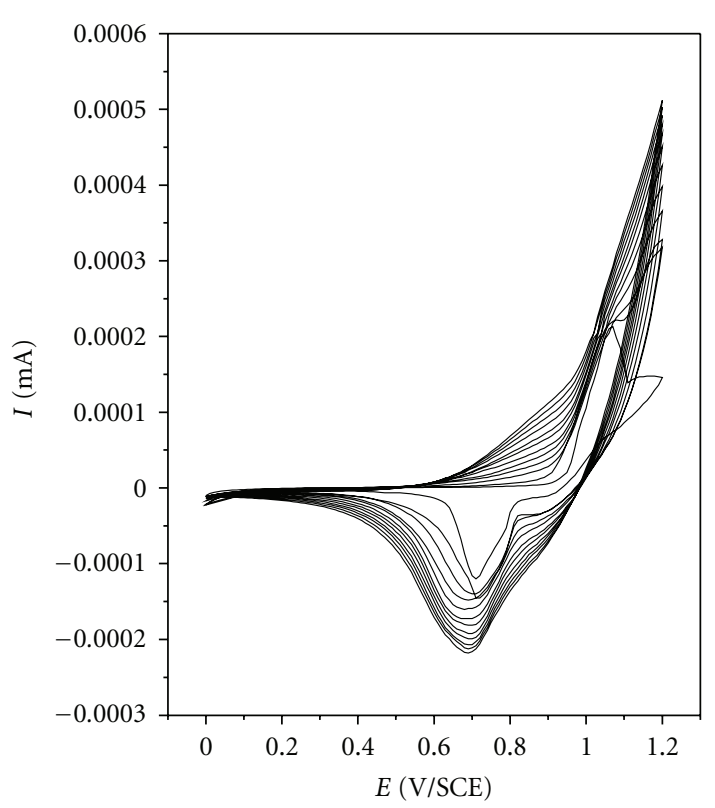

FIgURE 1: Electrochemical polymerization of $3 \mathrm{~T}$ (a) $1^{\text {rst }}$ cycle, repetitive cycling (b) in a solution of TBAP $0.1 \mathrm{M}$ in acetonitrile, scan rate $50 \mathrm{mV} / \mathrm{s}$.



FIgure 2: Cyclic voltammograms corresponding to P3T film in a solution of $\mathrm{CH}_{3} \mathrm{CN} / \mathrm{TBAP} 0.1 \mathrm{M}$, recording for different scan rates: (a) 10 , (b) 20 , (c) 50 , and (d) $100 \mathrm{mV} / \mathrm{s}$.

The film formed on the platinum electrode is electrochemically active and shows a reversible change of colour, a red in the oxidation state and blue in the reduction one. This phenomenon of P3T based on reversibly coloured electrochromic materials has become the subject of many interest applications. The electrochemical stability of the film was shown by repetitive voltammograms which remain essentially stable with cycling, and no evolution of the oxidation or the reduction current is observed. The stability of the oligothiophenes in air is already discussed in the 


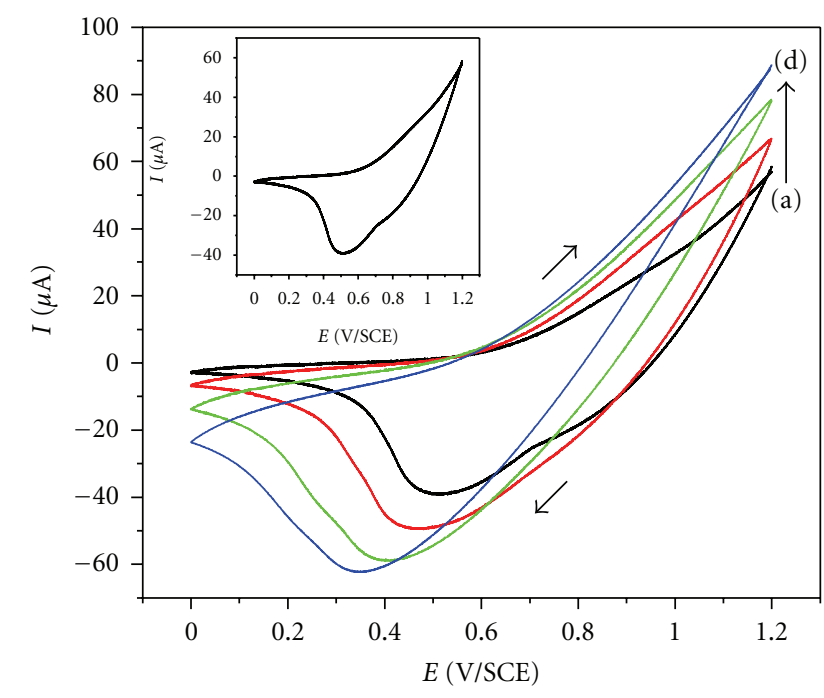

FIgURE 3: Cyclic voltammograms corresponding to P3T film in a $0.1 \mathrm{M}$ solution of TBAP in dichloromethane recording for different scan rates; (a) 10, (b) 20, (c) 50, and (d) $100 \mathrm{mV} / \mathrm{s}$.

literature $[3,34]$, and it is one of the most important properties of polyoligothiophenes.

The film of P3T was furthermore studied in $\mathrm{CH}_{2} \mathrm{Cl}_{2} /$ TBAP in absence of monomer. The corresponding voltamperograms are presented in Figure 3. Also it can be shown that the film can oxide and reduce, and practically the same allure of voltammograms is obtained; however, the electroactivity of the film in $\mathrm{CH}_{3} \mathrm{CN}$ was more defined and has a high oxidation current.

The voltammogram obtained here do not show clearly the anodic peaks except in the return scan; we observe a peak at $0.51 \mathrm{~V}$ attributable to the reduction of the film deposited on the electrode. So, contrary to the analysis realized in acetonitrile medium, in dichloromethane, the oxidation peak is poorly defined and is concealed, probably because of strong participation of capacitive current. The current intensity of the anodic and cathodic peak increases with scan rate. Also, the waves and the oxidation peaks do not appear when curves are recorded with high scan rates ( $\mathrm{v}>20 \mathrm{mV} / \mathrm{s}$ ), this is the result of the participation of a large capacitive current which becomes important as the scan rate increases. The difference $(\Delta E p)$ between the oxidation potential and the reduction one increases with the scan rates. The proportionality of the peak intensity to the scan rates suggests that the oxidation of electroactive polymer obtained on the electrode surface is limited by a diffusional process [30].

These results suggest that the thickness of the film is smaller than the diffusion layer thickness of counteranions on the cyclic voltammetric time scale used here, which must diffuse in and out during the doping and dedoping processes. The oxidation peaks shifted to more positive potential at scan rates increase; this suggests that as explained in reference [33] (i) the electron transfer from the electrode to the polymer film may be slow; (ii) the rate of electron transfer may be controlled by the diffusion of counter ions at a scan rate faster
TABLE 1: Electrical parameters corresponding to $\mathrm{P} 3 \mathrm{~T}$ in $\mathrm{CH}_{3} \mathrm{CN}$ / TBAP and in $\mathrm{CH}_{2} \mathrm{Cl}_{2}$ /TBAP.

\begin{tabular}{lcc}
\hline & $\mathrm{CH}_{3} \mathrm{CN} / \mathrm{TBAP}$ & $\mathrm{CH}_{2} \mathrm{Cl}_{2} / \mathrm{TBAP}$ \\
\hline $\operatorname{Re}(\Omega)$ & 100 & 500 \\
$\operatorname{Rct}(\Omega)$ & 500 & 2600 \\
$C(\mu \mathrm{F})$ & 0.019 & 0.036 \\
\hline
\end{tabular}

than $10 \mathrm{mV} / \mathrm{s}$; and/or (iii) the ohmic potential drop across the film may be significant.

3.3. Electrochemical Impedance Spectroscopy Characterization. Figure 4 gives the Nyquist plots of the electrodes coated by $\mathrm{P} 3 \mathrm{~T} / \mathrm{Pt}$, obtained in solution of $\mathrm{CH}_{3} \mathrm{CN} / \mathrm{TBAP} 0.1 \mathrm{M}$ (Figure 4(a)) and in $\mathrm{CH}_{2} \mathrm{Cl}_{2} / \mathrm{TBAP} 0.1 \mathrm{M}$ (Figure 4(b)). It can be seen that the two impedance curves have a semicircle in the high-frequency region for each medium, and the semicircle in acetonitrile is smaller than that in dichloromethane. The high-frequency part gives electrolyte resistance $(R \mathrm{e})$ by the distance from the original value, and the width of the semicircle gives the estimated impedance of the studied film, that is, ohmic resistance or ionic chargetransfer resistance (Rct) of the polymer-solution interface by the intercept of the semicircle with the real axis $[35,36]$. This behaviour is typical of impedance diagram of polymer film-coated metals in the asymmetric metal/film/electrolyte configuration [37].

Towards low or middle frequency region, the impedance diagrams show a straight line with slope of $45^{\circ}$ which indicates a diffusion-controlled Warburg behavior, attributable to the semiinfinite diffusion of protons at the polymerelectrolyte interface [38].

From the Nyquist plots, the kinetic parameters can be easily deduced. The value of transfer resistance allows us to determine the corresponding capacity $C$ (capacitance of the interface electrode/polymer), using the relationship: $2 \pi f R C=$ 1 for the frequency where the imaginary part has a maximum value on the half semicircle. The obtained parameters from the impedance plots of $\mathrm{P} 3 \mathrm{~T}$ are presented in Table 1.

As shown from Table 1, the values of $R \mathrm{e}, R \mathrm{ct}$, and $C$ are less important in acetonitrile than in dichloromethane medium, indicating that the charge-transfer process of $\mathrm{P} 3 \mathrm{~T}$ on the Pt electrode is more easier and fast in acetonitrile than in dichloromethane, and the film in $\mathrm{CH}_{2} \mathrm{Cl}_{2}$ has a high resistance. These results confirmed what we obtained in cyclic voltametry.

Generally, the electrochemically results obtained from the impedance diagrams of conducting organic polymers are modelled by an equivalent electrical circuit. Many of them have been proposed, in the literature, and in general, for the most part of cases, the equivalent circuit can be assimilated to a circuit of the Randles model, more or less modified according to the experimental conditions. The electrochemical parameters of P3T film are modelled by Randles circuit (Figure 5), which gives the uncompensated electrolyte resistance and serially connected to the capacitance of double 


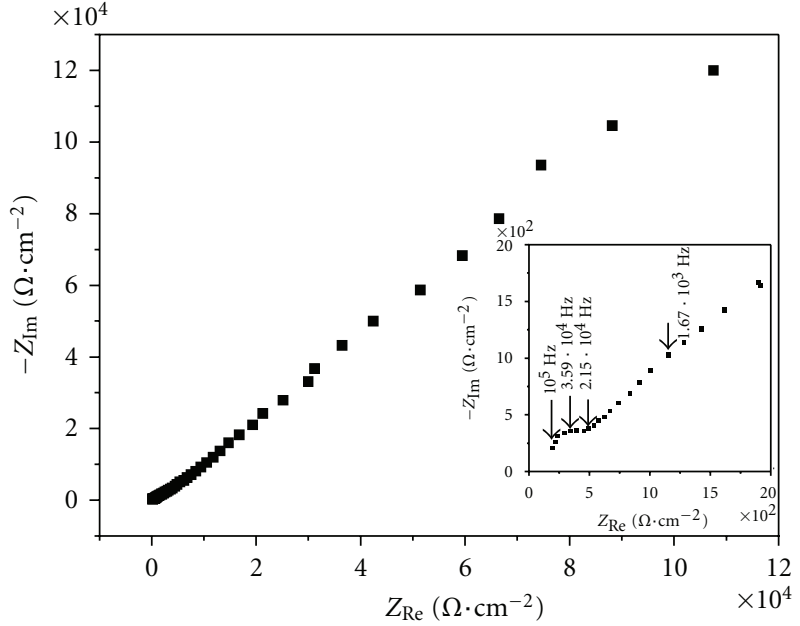

(a)

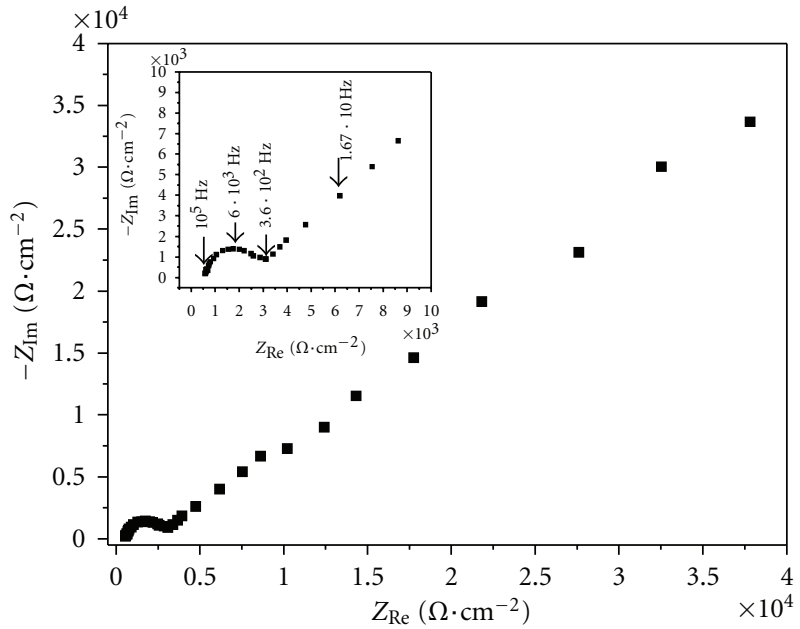

(b)

FIGURe 4: Nyquist plots of Pt modified electrode with P3T, recorded in: (a) $\mathrm{CH}_{3} \mathrm{CN} / \mathrm{TBAP}$, (b) $\mathrm{CH}_{2} \mathrm{Cl}_{2} / \mathrm{TBAP}$. Plots were recorded in the frequency range from $10^{5} \mathrm{~Hz}$ to $10^{-3} \mathrm{~Hz}$ at free potential.



FIGURE 5: Electrical equivalent circuit corresponding to P3T/ electrode interface (Randles circuit).

layer which is in parallel with the resistance of the charge transfer and Warburg impedance.

\section{Conclusion}

Electrochemical characterisation of P3T film was carried out using CV and EIS techniques. CV measurements showed that the electroactivity of polyterthiophene films intensity increases with increase of scan rates and it is more important in $\mathrm{CH}_{3} \mathrm{CN}$ than in $\mathrm{CH}_{2} \mathrm{Cl}_{2}$. However, the reduction peak currents are broader and displaced to more negative potential. EIS revealed that, at high frequencies, charge-transfer process dominates with a semicircle, and at low frequencies, diffusion process dominates with a slope line of $45^{\circ}$. The electrical parameters were found to be more significant in $\mathrm{CH}_{3} \mathrm{CN}$.

\section{References}

[1] M. Biserni, A. Marinangeli, and M. Mastragostino, "Doiped polydithienothiophene: a new cathode-active material," Journal of the Electrochemical Society, vol. 132, no. 7, pp. 15971601, 1985.

[2] G. Schopf and G. Kossmehl, Advances in PolymerScience, vol. 34, p. 1, 1997.
[3] C. A. Cutler, A. K. Burrell, D. L. Officer, C. O. Too, and G. G. Wallace, "Effect of electron withdrawing or donating substituents on the photovoltaic performance of polythiophenes," Synthetic Metals, vol. 128, no. 1, pp. 35-42, 2002.

[4] T. A. Skotheim, R. L. Elsenbaumer, and J. R. Reynolds, Handbook of Conducting Polymers, Marcel Dekker, New York, NY, USA, 1997.

[5] J. Roncali, "Conjugated poly(thiophenes): synthesis, functionalization, and applications," Chemical Reviews, vol. 92, no. 4, pp. 711-738, 1992.

[6] R. D. McCullough, "The chemistry of conducting polythiophenes," Advanced Materials, vol. 10, no. 2, pp. 93-116, 1998.

[7] L. B. Groenendaal, F. Jonas, D. Freitag, H. Pielartzik, and J. R. Reynolds, "Poly(3,4-ethylenedioxythiophene) and its derivatives: past, present, and future," Advanced Materials, vol. 12, no. 7, pp. 481-494, 2000.

[8] E. M. Genies, G. Bidan, and A. F. Diaz, "Spectroelectrochemical study of polypyrrole films," Journal of Electroanalytical Chemistry, vol. 149, no. 1-2, pp. 101-113, 1983.

[9] T. A. Skotheim, Handbook of Conducting Polymers, Marcel Dekker, New York, NY, USA, 1986.

[10] Y. Wei, C.-C. Chan, J. Tian, G.-W. Jang, and K. F. Hsueh, "Electrochemical polymerization of thiophenes in the presence of bithiophene or terthiophene: kinetics and mechanism of the polymerization," Chemistry of Materials, vol. 3, no. 5, pp. 888897, 1991.

[11] S. N. Hoier and S.-M. Park, "Electrochemistry of conductive polymers xiv. In suit spectroelectrochemical and kinetic studies on poly(3-methylthiophene) growth," Journal of the Electrochemical Society, vol. 140, no. 9, pp. 2454-2463, 1993.

[12] M. Trueba, S. P. Trasatti, and S. Trasatti, "Electrocatalytic activity for hydrogen evolution of polypyrrole films modified with noble metal particles," Materials Chemistry and Physics, vol. 98, no. 1, pp. 165-171, 2006.

[13] V. Selvaraj, M. Alagar, and I. Hamerton, "Nanocatalysts impregnated polythiophene electrodes for the electrooxidation of formic acid," Applied Catalysis B, vol. 73, no. 1-2, pp. 172-179, 2007. 
[14] M. Boopathi, M.-S. Won, and Y.-B. Shim, "A sensor for acetaminophen in a blood medium using a $\mathrm{Cu}(\mathrm{II})$-conducting polymer complex modified electrode," Analytica Chimica Acta, vol. 512, no. 2, pp. 191-197, 2004.

[15] K. B. Crawford, M. B. Goldfinger, and T. M. Swager, " $\mathrm{Na}^{+}$specific emission changes in an ionophoric conjugated polymer," Journal of the American Chemical Society, vol. 120, no. 21, pp. 5187-5192, 1998.

[16] D. W. DeBerry, "Modification of the electrochemical and corrosion behavior of stainless steels with an electroactive coating," Journal of the Electrochemical Society, vol. 132, no. 5, pp. 1022-1026, 1985.

[17] H. Hammache, L. Makhloufi, and B. Saidani, "Corrosion protection of iron by polypyrrole modified by copper using the cementation process," Corrosion Science, vol. 45, no. 9, pp. 2031-2042, 2003.

[18] R. Hasanov and S. Bilgiç, "Monolayer and bilayer conducting polymer coatings for corrosion protection of steel in $1 \mathrm{M}$ $\mathrm{H}_{2} \mathrm{SO}_{4}$ solution," Progress in Organic Coatings, vol. 64, no. 4, pp. 435-445, 2009.

[19] C. Y. Wang, G. Tsekouras, P. Wagner et al., "Functionalised polyterthiophenes as anode materials in polymer/polymer batteries," Synthetic Metals, vol. 160, no. 1-2, pp. 76-82, 2010.

[20] P. Novák, K. Müller, K. S. V. Santhanam, and O. Haas, "Electrochemically active polymers for rechargeable batteries," Chemical Reviews, vol. 97, no. 1, pp. 207-281, 1997.

[21] B. Yin, C. Jiang, Y. Wang, M. La, P. Liu, and W. Deng, "Synthesis and electrochromic properties of oligothiophene derivatives," Synthetic Metals, vol. 160, no. 5-6, pp. 432-435, 2010.

[22] C. M. Casado, I. Cuadrado, M. Morán, B. Alonso, B. González, and J. Losada, "Redox-active ferrocenyl dendrimers and polymers in solution and immobilised on electrode surfaces," Coordination Chemistry Reviews, vol. 185-186, pp. 53-79, 1999.

[23] L. M. Goldenberg, M. R. Bryce, and M. C. Petty, "Chemosensor devices: voltammetric molecular recognition at solid interfaces," Journal of Materials Chemistry, vol. 9, no. 9, pp. 1957-1974, 1999.

[24] J. Chen, A. K. Burrell, G. E. Collis et al., "Preparation, characterisation and biosensor application of conducting polymers based on ferrocene substituted thiophene and terthiophene," Electrochimica Acta, vol. 47, no. 17, pp. 2715-2724, 2002.

[25] N. Maouche and B. Nessark, "Electrochemical behavior of polyterthiophene-coated types 304 and 316 stainless steels and its corrosion performance," Corrosion, vol. 64, no. 4, pp. 315324, 2008.

[26] B. Sari, M. Talu, F. Yildirim, and E. K. Balci, "Synthesis and characterization of polyurethane/polythiophene conducting copolymer by electrochemical method," Applied Surface Science, vol. 205, no. 1-4, pp. 27-38, 2002.

[27] S. Asavapiriyanont, G. K. Chandler, G. A. Gunawardena, and D. Pletcher, "The electrodeposition of polypyrrole films from aqueous solutions," Journal of Electroanalytical Chemistry, vol. 177, no. 1-2, pp. 229-244, 1984.

[28] D. L. Wakeham, S. W. Donne, W. J. Belcher, and P. C. Dastoor, "Electrochemical and morphological characterization of electrodeposited poly(2,2':5',2“-terthiophene) for photovoltaic applications," Synthetic Metals, vol. 158, no. 16, pp. 661-669, 2008.

[29] G. Tourillon and F. Garnier, "Structural effect on the electrochemical properties of polythiophene and derivatives," Journal of Electroanalytical Chemistry, vol. 161, no. 1, pp. 51-58, 1984.
[30] M. A. Sato, S. Tanaka, and K. Kaeriyama, "Electrochemical preparation of conducting poly(3-methylthiophene): comparison with polythiophene and poly(3-ethylthiophene)," Synthetic Metals, vol. 14, no. 4, pp. 279-288, 1986.

[31] G. Zotti, G. Schiavon, A. Berlin, and G. Pagani, "Thiophene oligomers as polythiophene models. 2. Electrochemistry and in situ ESR of end-capped oligothienyls in the solid state. Evidence for $\pi$-dimerization of hexameric polarons in polythiophene," Chemistry of Materials, vol. 5, no. 5, pp. 620-624, 1993.

[32] R. Berthelot, C. Rozé, M. M. Granger, and E. Raoult, "Anodic oxidation of various arylene-cyanovinylenes made of alternating fluorenyl, thienyl and/or phenyl units," Journal of Electroanalytical Chemistry, vol. 466, no. 2, pp. 144-154, 1999.

[33] T.-Y. Lee, Y.-B. Shim, and S. C. Shin, "Simple preparation of terthiophene-3'-carboxylic acid and characterization of its polymer," Synthetic Metals, vol. 126, no. 1, pp. 105-110, 2002.

[34] G. Schopf and G. Kossmehl, Advances in PolymerScience, vol. 34, p. 1, 1997.

[35] W. C. Chen, T. C. Wen, and A. Gopalan, "Negative capacitance for polyaniline: an analysis via electrochemical impedance spectroscopy," Synthetic Metals, vol. 128, no. 2, pp. 179-189, 2002.

[36] C. C. Hu and C. H. Chu, "Electrochemical impedance characterization of polyaniline-coated graphite electrodes for electrochemical capacitors-effects of film coverage/thickness and anions," Journal of Electroanalytical Chemistry, vol. 503, no. 1-2, pp. 105-116, 2001.

[37] L. Niu, Q. Li, F. Wei, X. Chen, and H. Wang, "Electrochemical impedance and morphological characterization of platinummodified polyaniline film electrodes and their electrocatalytic activity for methanol oxidation," Journal of Electroanalytical Chemistry, vol. 544, pp. 121-128, 2003.

[38] W. C. Chen, T. C. Wen, and A. Gopalan, "The inductive behavior derived from hydrolysis of polyaniline," Electrochimica Acta, vol. 47, no. 26, pp. 4195-4206, 2002. 




International Journal of

Medicinal Chemistry



Carbohydrate Chemistry

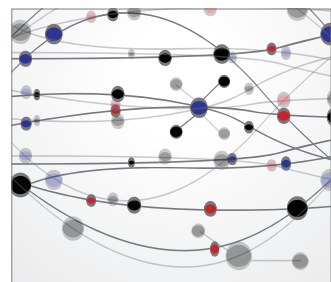

The Scientific World Journal
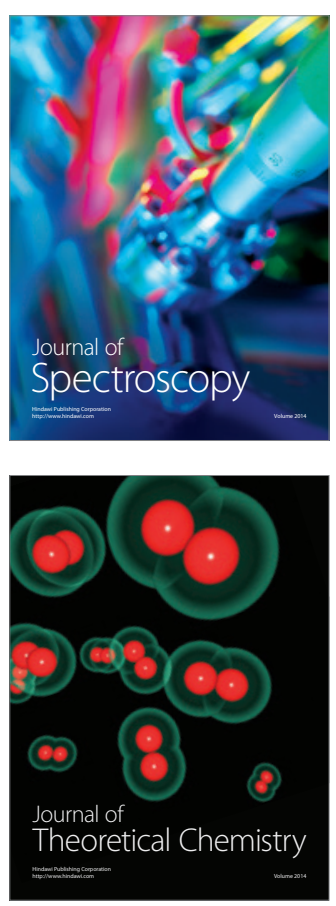
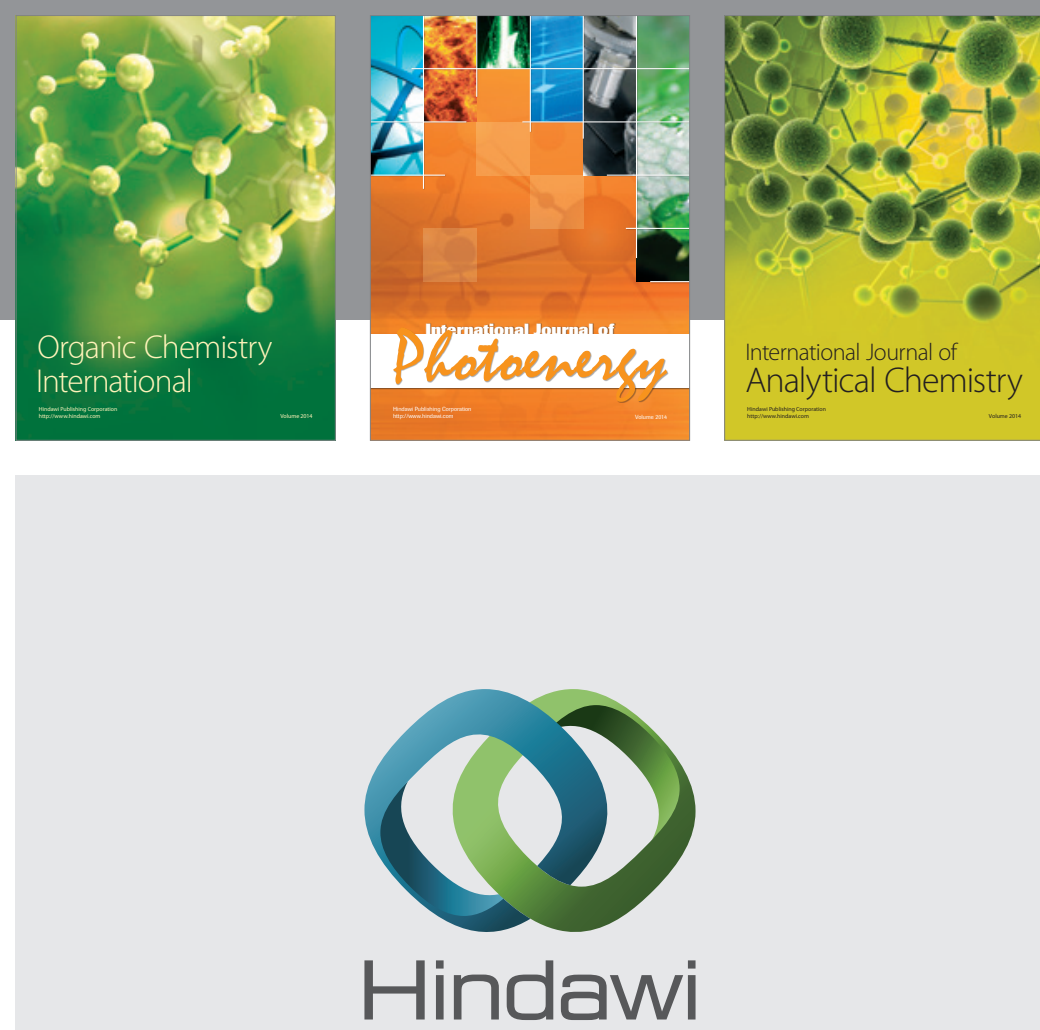

Submit your manuscripts at

http://www.hindawi.com
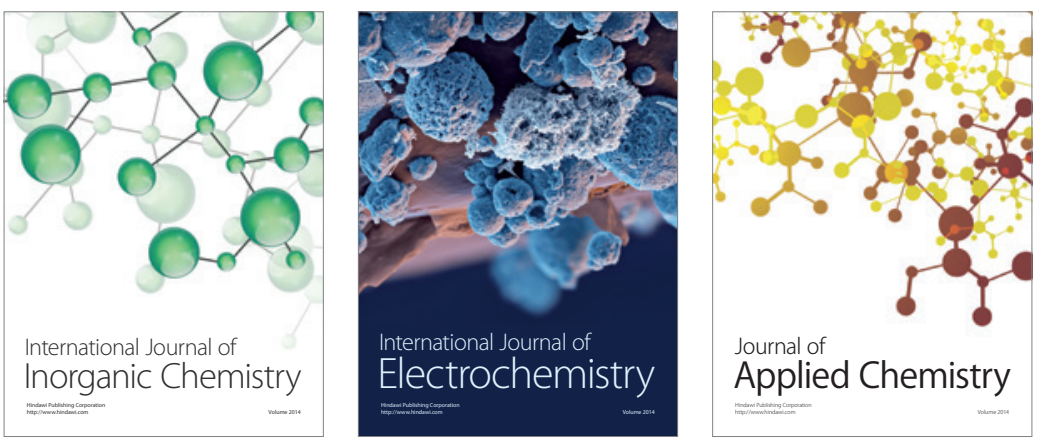

Journal of

Applied Chemistry
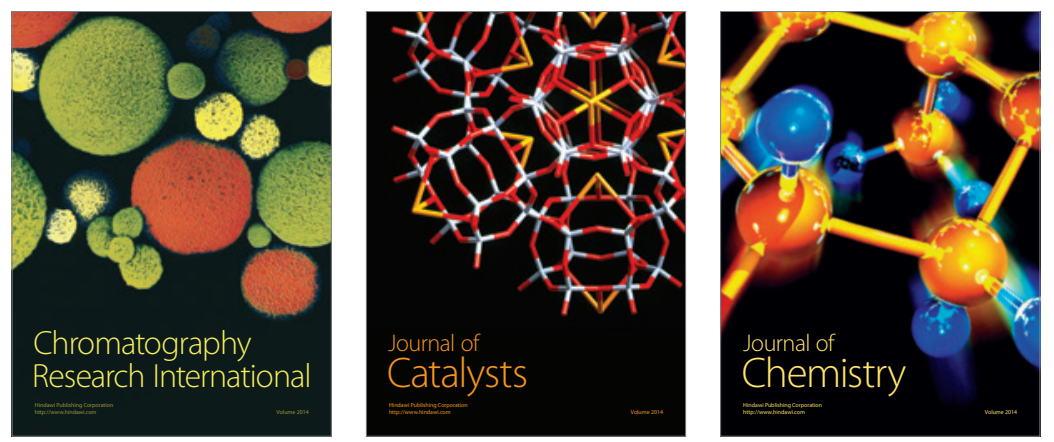
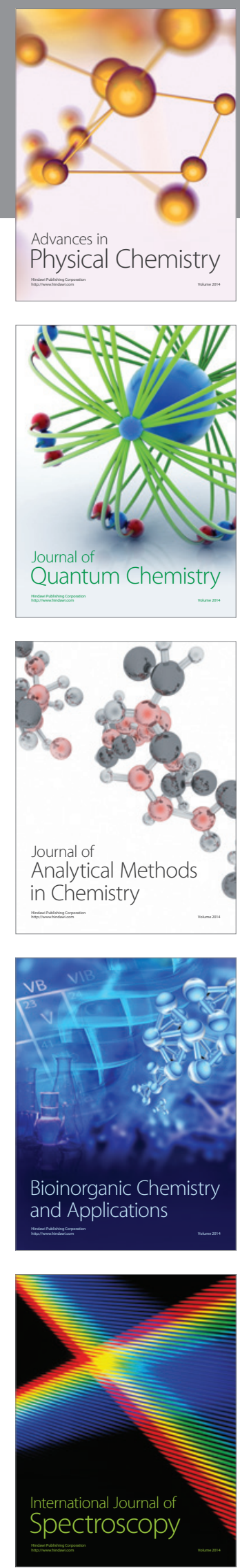